\title{
Correction to: A decade of service development: audit of service users' experience of a rural Psychiatry of Later Life (POLL) service
}

\author{
Memoona Usman ${ }^{1} \cdot$ Leona Lally $^{2} \cdot$ Sinead Costello $^{3} \cdot$ Aoife Kiely $^{4} \cdot$ Sabina Fahy ${ }^{5}$
}

Published online: 17 April 2021

(c) Royal Academy of Medicine in Ireland 2021

Correction to: Irish Journal of Medical Science (2021)

https://doi.org/10.1007/s11845-021-02540-3

The original article contains an error. In Abstract, the subheadings "Aims" contains an incorrect sentence and "Methodology" should also be a sub-heading which was incorrectly captured under Aims.

The original article has been corrected.

The original article can be found online at https://doi.org/10.1007/ s11845-021-02540-3.

Memoona Usman

drmemoonaanjum11@gmail.com

1 Senior Registrar in General Adult Psychiatry, Sligo Leitrim Mental Health Services, Markievicz House, Barrack Street, Sligo, Co Sligo, Ireland

2 Locum Consultant in General Adult Psychiatry, Clare Mental Health Services, Ennis, Co Clare, Ireland

3 Senior Registrar Psychiatry of Later Life, St Brendan's CNU, Ballinasloe Co, CreaghGalway, Ireland

4 C/O Galway Bay Medical Centre, General Practitioner, Dock Road, Galway, Ireland

5 Consultant Psychiatrist of Later Life, St Brendan's CNU, Ballinasloe Co, CreaghGalway, Ireland 